\title{
Miejsce Instytutu Historii PAN w przyszłych badaniach geograficzno-historycznych w Polsce
}

\author{
Marek Słoń \\ https://orcid.org/0000-0001-8208-4743 \\ Instytut Historii im. Tadeusza Manteuffla Polskiej Akademii Nauk
}

Zarys treści: Zakład Atlasu Historycznego kończy serię map szczegółowych ziem polskich Korony w XVI w. Wraz z zespołem słownika historyczno-geograficznego ziem polskich w średniowieczu jest ważnym na świecie ośrodkiem badań geograficzno-historycznych oraz edytorstwa i refleksji metodologicznej. Jego przyszłość zależy od profilu badawczego Instytutu Historii PAN. Jeżeli priorytetem nie staną się wieloletnie zespołowe projekty łączące prace dokumentacyjne ze ściśle badawczymi - grozi mu likwidacja.

Stowa kluczowe: geografia historyczna, Instytut Historii PAN, atlas, Polska

Zakład Atlasu Historycznego to zespół, który pod różnymi nazwami działa od początku istnienia Instytutu Historii Polskiej Akademii Nauk, czyli 1953 r. ${ }^{1}$ Jego zadaniem było i jest przygotowanie serii „Atlas historyczny Polski. Mapy szczegółowe XVI wieku"2. Ukazuje się ona od lat sześćdziesiątych XX w. i jak dotąd objęła dziesięć województw ${ }^{3}$. Od tomu wielkopolskiego

\footnotetext{
${ }^{1}$ M. Wilska, Atlas Historyczny Polski, w: Instytut Historii Polskiej Akademii Nauk 1953-2003, red. S.K. Kuczyński, Warszawa 2003, s. 151-161.

${ }^{2}$ W. Pałucki, Przedmowa, w: S. Wojciechowski, Województwo lubelskie w drugiej połowie XVI w., Warszawa 1966 (Atlas historyczny Polski, Mapy szczegółowe XVI wieku, 3), s. 7-12; H. Rutkowski, Atlas historyczny Polski, w: Towarzystwo Naukowe Warszawskie. Sto lat działalności, red. E. Wolnicz-Pawłowska, W. Zych, Warszawa 2009, s. 115-121; tenże, Work on the historical atlas of the sixteenth-century Poland, „Polish Carthographical Review", 50 (4), 2018, s. 223-231.

${ }^{3}$ Województwo lubelskie w drugiej połowie XVI wieku, red. W. Pałucki, oprac. S. Wojciechowski, Warszawa 1966 (Atlas historyczny Polski. Mapy szczegółowe XVI wieku, 3); Mazowsze w drugiej połowie XVI w., red. W. Pałucki, Warszawa 1973 (Atlas historyczny Polski. Mapy szczegółowe XVI wieku, 7); Województwo sandomierskie w drugiej połowie XVI w., red. W. Pałucki, Warszawa 1993 (Atlas historyczny Polski. Mapy szczegółowe XVI wieku, 2); Województwo sieradzkie i województwo tęczyckie w drugiej połowie XVI w., red. H. Rutkowski, Warszawa 1998 (Atlas historyczny Polski. Mapy szczegółowe XVI
}

Abstract: The Department of Historical Atlas finishes a series of detailed maps of lands of the Polish Crown in the $16^{\text {th }}$ century. Together with the team of the Historical-Geographical Dictionary of the Polish Lands in the Middle Ages, it makes an important centre of geographical and historical research as well as editing works and methodological reflection on a global scale. Its future depends on the research profile of the Tadeusz Manteuffel Institute of History of the Polish Academy of Sciences: it is threatened with closure if long-term, team projects combining documentary and strictly research work are not a priority.

Keywords: historical geography, Institute of History of the Polish Academy of Sciences, atlas, Poland

towarzyszy jej cyfrowa edycja rejestrów poborowych z drugiej połowy XVI w., a wydaniu drukowanemu - udostępnienie treści mapy w formie przestrzennej bazy danych ${ }^{4}$. Obecnie trwają równoległe prace nad ostatnimi przewidzianymi

wieku, 5); Województwo krakowskie w drugiej połowie XVI w., red. H. Rutkowski, Warszawa 2008 (Atlas historyczny Polski. Mapy szczegółowe XVI wieku, 1); Wielkopolska w drugiej połowie XVI wieku, red. K. Chłapowski, M. Słoń, Warszawa 2017 (Atlas historyczny Polski. Mapy szczegółowe XVI wieku, 4). Redaktorem serii w tomach 1, 2 i 5 był Stanisław Trawkowski, w tomie 1 razem z nim Małgorzata Wilska, a w tomie 4 - Marek Stoń i Henryk Rutkowski.

${ }^{4}$ Ziemie polskie Korony w XVI w. Przestrzenna baza danych (http:// www.atlasfontium.pl/index.php?article=korona, dostęp: 26 czerwca 2019); M. Ston, Foreword to the British edition, w: Historical Atlas of Poland in the $2^{\text {nd }}$ half of the $16^{\text {th }}$ century: voivodeships of Cracow, Sandomierz, Lublin, Sieradz, Łęczyca, Rawa, Ptock and Mazovia, ed. M. Słoń, Frankfurt am Main 2014, s. 1-6; Atlas historyczny Polski. Rejestry poborowe województwa kaliskiego wXVI w. red. M. Słoń (Atlas Źródeł i Materiałów do Dziejów Dawnej Polski, http://www.atlasfontium. pl/index.php?article=kaliskie, dostęp: 26 czerwca 2019); Atlas historyczny Polski. Rejestry poborowe województwa poznańskiego w XVI w. red. M. Stoń (Atlas Żródet i Materiatów do Dziejów Dawnej Polski, http://www.atlasfontium.pl/index.php?article = poznanskie, dostęp: 26 czerwca 2019); A. Borek, T. Panecki, Cartographic visualization of historical source data on AtlasFontium.pl, w: Progress in cartography, ed. G. Gartner, M. Jobst, H. Huang, Cham 2016, s. 65-81. 
w pierwotnym zamierzeniu tomami (dotyczącymi Kujaw i Podlasia) oraz dodatkowo - nad nowym opracowaniem Prus Królewskich. W realizowanym projekcie mieszczą się też prace uzupełniające odnośnie do reszty ziem polskich Korony, które polegaja przede wszystkim na uzupełnieniu dokumentacji wydanych wcześniej tomów. Zadania muszą być ukończone w 2020 r., kiedy to nastąpi zamknięcie zakładu w obecnym kształcie.

W minionej dekadzie aktywność naukowa członków zespołu wykroczyła daleko poza przygotowywanie samej serii. Ostatnie lata wiązały się z realizacją około dziesięciu różnych projektów dotyczących geografii historycznej i edytorstwa źródet ${ }^{5}$. Korzysta się przy nich z dorobku i umiejętności, jakie przyniosły prace atlasowe, ale też wykracza daleko poza nie. Do zakładu dołącza coraz więcej osób, które nie mają żadnego związku z głównym projektem. Stopniowo zespół stał się ważnym ośrodkiem badań geograficzno-historycznych w Polsce, przez co nie można zamknać pytania o jego przyszłość prostą odpowiedzią o zakończeniu serii.

Badania geograficzno-historyczne w IH PAN nie ograniczają się zresztą do prac tego jednego zespołu. Istotną rolę odgrywa również kierowany przez Tomasza Jurka Zakład Słownika Historyczno-Geograficznego Ziem Polskich w Średniowieczu, składający się z dwóch pracowni krakowskiej i poznańskiej - oraz zespołu mazowiecko-podlaskiego. Prowadzone tam prace charakteryzuje znakomity poziom warsztatowy, a metoda $\mathrm{w}$ ramach

\footnotetext{
${ }^{5} \mathrm{~Np}$. „Ontologiczne podstawy budowy historycznych systemów informacji geograficznej” (Bogumił Szady), „Księgi konsystorza kaliskiego z lat 1504-1534” (Arkadiusz Borek), „Cyfrowa edycja kaliskich ksiąg ziemskich i grodzkich z przełomu XV i XVI wieku” (Tomasz Związek), „Elektroniczna edycja ksiąg sądowych powiatu kaliskiego z lat 1587-1593” (Michał Gochna), „Cyfrowe edycje map dawnych: perspektywy i ograniczenia na przykładzie Mapy geograficzno-wojskowej i statystycznej Wielkopolski (1807-1812)” (Tomasz Panecki), „Atlas historyczny miast polskich: Kalisz" (Urszula Sowina), „Annual Fairs in Greater Poland from the Late Middle Ages to the Deluge (1385-1655)" (Anna P. Orłowska), „Sieć osadnicza Warmii - badania wstępne” (Wiesława Duży).
}

przygotowywania serii słownikowej stanowi cenny wkład nauki polskiej do światowej historiografii i geografii zarazem6. Członkowie tego zespołu prowadzą również badania i przedsięwzięcia edytorskie, które wykraczają poza główne dzieło 7 . Żadna inna jednostka w instytucie nie specjalizuje się w geografii historycznej, choć zdarzają się projekty związane z tym kierunkiem studiów.

Do 2011 r. oba wspomniane wyżej zakłady finansowane były z dotacji na utrzymanie potencjału badawczego, co z jednej strony dawało im stabilność funkcjonowania, ale z drugiej ograniczało możliwości rozwoju. Przełom przyniósł Narodowy Program Rozwoju Humanistyki. Wysoko finansowane pięcioletnie projekty pozwoliły na znaczne zwiększenie liczby osób zaangażowanych w prace, podniesienie wynagrodzeń oraz finansowanie wyjazdów na kwerendy i konferencje międzynarodowe. Radykalna zmiana charakteru programu po 2015 r. wykluczyła jednak możliwość kontynuowania prac $\mathrm{w}$ dotychczasowym trybie. Wątpliwe też, czy zespół słownikowy w ogóle będzie mógł się ubiegać o kolejną dotację, a nawet jeśli ją otrzyma, to przyznana kwota wystarczy na utrzymanie mniej niż jednej trzeciej jego obecnego

\footnotetext{
${ }^{6}$ Stownik historyczno-geograficzny ziem polskich w średniowieczu. Edycja elektroniczna, red. T. Jurek, 2010-2016 (http://www.slownik.ihpan. edu.pl/index.php, dostęp: 26 czerwca 2019) (tu m.in. lista słowników wydanych drukiem, poza trzema ostatnimi); K. Górska-Gołaska, Stownik historyczno-geograficzny ziem polskich w średniowieczu, w: Instytut Historii Polskiej Akademii Nauk 1953-2003, red. S.K. Kuczyński, Warszawa 2003, s. 137-150.

7 Ilustracją zainteresowań badawczych pracowników zakładu słownika są publikacje z ostatnich lat: T. Jurek, Średniowieczny katalog biskupów poznańskich w Roczniku lubińskim ukryty, „Studia Źródłoznawcze”, 54, 2016, s. 51-58; P. Dembiński, Poznańska kapituła katedralna schyłku wieków średnich. Studium prozopograficzne 1428-1500, Poznań 2012; Najstarsza pleszewska księga radziecka. Zapiski z lat 1485-1519, wyd., przeł. i oprac. A. Kozak, Poznań 2014; J. Laberschek, Sieć wodna średniowiecznego Krakowa i jej gospodarcze wykorzystanie, Warszawa 2016; J. Szyszka, Formowanie i organizacja dóbr monarszych w ziemi Iwowskiej od połowy XIV do początku XVI wieku, Kraków 2016. Waldemar Bukowski wraz z zespołem (Zdzisławem Nogą, Zdzisławem Budzyńskim, Andrzejem Janeczkiem i Bogusławem Dybasiem) wydaje od 2012 r. serię map: Galicja na józefińskiej mapie topograficznej 1779-1783, np. t. 1, cz. A, sekcje 1-30: Die Josephinische Landesaufnahme von Galizien 1779-1783.
} 
składu osobowego. Dodatkowo w międzyczasie ograniczono środki statutowe i zarazem skierowano je na inne cele. Bliska przyszłość finansowa instytutu nie wygląda dobrze, a dalsza zależy od wyniku kolejnej ewaluacji. W tej chwili rysuje się dość ponura perspektywa braku finansowania obu zakładów i zwolnienia zdecydowanej większości pracowników, a oba zespoły stanowią w sumie około dwudziestu procent osób zatrudnionych w instytucie.

W tym kontekście warto postawić pytanie o rolę IH PAN w badaniach historycznych w Polsce. Pion dokumentacyjny pełni obecnie w pewnym stopniu rolę usługową wobec polskiej historiografii. Wypracowuje podstawowe narzędzia warsztatowe, jak słowniki, atlasy czy bibliografie, z których korzysta całe środowisko. Wyższe finansowanie w ramach NPRH pozwolito stworzyć ośrodek badań geograficzno-historycznych widoczny na mapie naukowej nie tylko Polski, ale i świata. Jest to miejsce pełniące kilka ważnych funkcji. Kontynuowane są tu działania nad tworzeniem niezbędnych $\mathrm{w}$ pracy historyka zasobów, gromadzonych i udostępnianych nie tylko $\mathrm{w}$ formie tradycyjnej, ale z wykorzystaniem najnowszych zdobyczy techniki. Wypracowuje się tu nowe rozwiązania, ustala standardy i rozwija refleksję metodologiczną ${ }^{8}$. Kształtuje się też wreszcie stabilną sieć kontaktów i wymiany na całym świecie. Wszystko to możliwe jest dzięki harmonijnemu połączeniu

\footnotetext{
${ }^{8} \mathrm{~Np} .:$ B. Szady, Spatio-temporal databases as research tool in historical geography, „Geographia Polonica”, 89 (3), 2016, s. 359-370; A. Borek, Baza danych jako forma edycji wykazów święceń duchowieństwa, „Roczniki Humanistyczne”, 64 (2), 2016, s. 59-88; M. Gochna, Polish nobility seals in the "recognitiones" of the Kalisz district in 1591. The perspective of an Edition, w: Editionswissenschaftliches Kolloquium 2015. Die Geschichte im Bild, Hrsg. H. Flachenecker, K. Kopiński, J. Tandecki, Toruń 2016, s. 103-108; T. Panecki, T. Związek, The so-called Dutch colonization in $18^{\text {th }} \mathrm{C}$. Greater Poland: research project on AtlasFontium.pl WebGIS platform, w: Digital approaches to cartographic heritage, ed. E. Livieratos, Saloniki 2016, s. 344-356; A. Borek i in. Technical and methodological foundations of digital indexing of medieval and early modern court books, „Digital Scholarship in the Humanities", 30, 2019 (https://doi.org/10.1093/llc/fqz030, dostęp: 26 czerwca 2019).
}

zespołowej i indywidualnej pracy dokumentacyjnej i ściśle badawczej.

W innych zakładach nie występują niektóre z tych elementów. W przypadku Zakładu Bibliografii Historii Polskiej oraz Zakładu Polskiego Słownika Biograficznego badania indywidualne i szersza refleksja metodologiczna oraz aktywność publikacyjna są marginalne, a w pionie badawczym, skupiającym zdecydowaną większość samodzielnych pracowników naukowych, projekty zespołowe odgrywają co najwyżej drugorzędną rolę. Prace indywidualne, choć często prowadzone na wysokim poziomie, lub wspólne projekty angażujące ich uczestników w niewielkim stopniu nie wykorzystują możliwości, jakie instytutom PAN daje brak obciążeń dydaktycznych. W ten sposób powielane są zadania, które mogą być - i z powodzeniem są - realizowane przez uniwersytety. Ich rosnąca dominacja w aktywności całego instytutu, a przede wszystkim w zagospodarowywaniu jego zasobów finansowych, czyni z IH PAN raczej uprzywilejowanego konkurenta innych placówek niż dobro wspólne polskiej historiografii.

Stoimy zatem przed wyborem między kontynuacją lub wręcz pogłębieniem tego stanu (co bardziej prawdopodobne) a zmianą w kierunku wykorzystania doświadczeń zespołu atlasowego i uczynienia zeń wzorca dla pozostałych. Rozważania na temat roli IH PAN w przyszłych badaniach historyczno-geograficznych w Polsce mają sens jedynie przy założeniu pójścia drugą z tych dróg i tę perspektywę przedstawiam poniżej.

Stan i kierunki geografii historycznej w Polsce zostały niedawno przedstawione przez Bogumiła Szadego i w mojej opinii wciąż jest to aktualny obraz ${ }^{9}$ Nurt ten obecny jest w najważniejszych ośrodkach akademickich w Polsce i obejmuje bardzo zróżnicowane zagadnienia. W naukach

\footnotetext{
${ }^{9}$ B. Szady, Geografia historyczna w Polsce - rozwój i perspektywy, „Studia Geohistorica”, 1, 2013, s. 19-38.
} 
historycznych nie ma stabilnego zaplecza instytucjonalnego poza IH PAN. Żadna inna jednostka nie jest obecnie w stanie prowadzić badań geograficzno-historycznych w takiej skali, jak robią to podlegające mu zespoły atlasowy i słownikowy. Wynika z tego szczególna odpowiedzialność instytutu. Na przykładzie geografii historycznej widać tu rolę, jaką może i powinien on pełnić $\mathrm{w}$ polskiej historiografii.

Instytut powinien nie tylko utrzymać, ale także rozwinąć wiodący ośrodek geografii historycznej czerpiący z dotychczasowych doświadczeń i zasobów, także ludzkich. Kontynuacji wymaga na pewno, choć może w zmienionej formule, słownik geograficzno-historyczny. Obok niego widzę miejsce przede wszystkim dla trzech zespołów i zarazem kierunków badań. Prace atlasowe należy kontynuować dla ziem wschodnich Rzeczypospolitej. Inna baza źródłowa niż w przypadku ziem polskich Korony skłania do skoncentrowania się na wieku XVIII, co nie wyklucza utrzymania dotychczasowych ram chronologicznych np. dla Rusi Czerwonej. Prace te powinny w większym stopniu niż dotychczas mieć charakter źródłoznawczy i edytorski. Drugim kierunkiem angażującym badaczy z różnych zakładów są dzieje miast i studia porównawcze nad ich przestrzenią, a wiodącym zadaniem byłaby w nim seria „Atlasu Historycznego Miast Polskich"10. Dla obu tych nurtów niezbędny jest trzeci - silne zaplecze kartograficzne i techniczne. Gromadzenie, analiza i prezentacja danych przestrzennych (zarówno źródłowych, jak i krytycznych) wymaga zastosowania Systemu Informacji Geograficznej i dedykowanych aplikacji. Wypracowanie cyfrowych narzędzi odpowiadających potrzebom współczesnej historiografii to zadanie nie tylko dla programistów, ale także dla współpracujących z nimi historyków oraz przedstawicieli innych dyscyplin, jak

\footnotetext{
${ }^{10}$ R. Czaja, Historical atlas of Polish towns. Between source edition and the cartographic presentation of research on the history of towns, „Studia Geohistorica”, 6, 2018, s. 80-89.
}

geografia, filozofia (ontologia, epistemologia), językoznawstwo czy informacja naukowa. Efektem tych prac będzie stale rozwijana baza danych przestrzennych odnoszących się do przeszłości. Wymaga ona ciągłej opieki, aktualizacji i stopniowej integracji z innymi zasobami, jak geoportal ${ }^{11}$ (współczesne dane przestrzenne) czy bazy biograficzne (genealogiczne, prozopograficzne). Niezbędne jest wreszcie wprowadzanie tych narzędzi do warsztatu poprzez włączanie odpowiednich umiejętności do programu nauczania uniwersyteckiego, organizację kursów, publikacje o charakterze dydaktycznym (nie tylko tekstowe!), promocję medialną czy wreszcie stałą pomoc techniczną.

Sądzę, że podane tu przykłady kierunków rozwoju badań geograficzno-historycznych mogą być inspiracją dla innych zakładów IH PAN (zarówno badawczych, jak dokumentacyjnych). Jest to jednak pole do działania dla tych zespołów i Rady Naukowej, a nie piszącego te słowa. Warto jedynie zaznaczyć, że aktywność innych zakładów instytutu, pełniących podobną rolę w nauce, byłaby nie tylko korzystnym, ale wręcz pożądanym elementem zapewniającym wzajemną stymulację różnych nurtów i szkół badawczych.

Powyższe postulaty wynikają z dwóch zarysowanych już wyżej przesłanek. Po pierwsze, wykorzystano by potencjał aktualnego zespołu, a po drugie - i to jest kwestia ważniejsza - zdają się to być w naszej ocenie najpilniejsze potrzeby geografii historycznej w Polsce, a po trosze również poza jej granicami. Istotniejsze jest jednak to, co sądzi na ten temat całe środowisko historyczne, a właściwie część zainteresowana takim nurtem badań. Należy więc traktować powyższą propozycję jako punkt wyjścia do dalszej debaty.

\footnotetext{
${ }^{11}$ Polski geoportal krajowy nie oferuje obecnie wśród map tematycznych danych, które odnosiłyby się do przeszłości: Mapy tematyczne, „Geoportal Infrastruktury Informacji Przestrzennej" (https://www.geoportal. gov.pl/dane/mapy-tematyczne\#, dostęp: 9 lipca 2019).
} 


\section{Bibliografia}

Atlas historyczny Polski. Rejestry poborowe województwa kaliskiego w XVI w., red. M. Słoń (Atlas Źródeł i Materiałów do Dziejów Dawnej Polski, http:// www.atlasfontium.pl/index.php?article=kaliskie, dostęp: 26 czerwca 2019).

Atlas historyczny Polski. Rejestry poborowe województwa poznańskiego $w X V I w$., red. M. Słoń (Atlas Źródeł i Materiałów do Dziejów Dawnej Polski, http:// www.atlasfontium.pl/index.php?article=poznanskie, dostęp: 26 czerwca 2019).

Borek A., Baza danych jako forma edycji wykazów świeceń duchowieństwa, „Roczniki Humanistyczne”, 64 (2), 2016.

Borek A., Panecki T., Cartographic visualization of historical source data on AtlasFontium.pl, w: Progress in cartography, ed. G. Gartner, M. Jobst, H. Huang, Cham 2016.

Borek A., Związek T., Gochna M., Słomski M., Myrda G., Słoń M., Technical and methodological foundations of digital indexing of medieval and early modern court books, „Digital Scholarship in the Humanities", 30, 2019 (https://doi.org/10.1093/ llc/fqz030, dostęp: 26 czerwca 2019).

Czaja R., Historical atlas of Polish towns. Between source edition and the cartographic presentation of research on the history of towns, „Studia Geohistorica”, 6, 2018.

Dembiński P., Poznańska kapituta katedralna schytku wieków średnich. Studium prozopograficzne 1428 1500, Poznań 2012.

Digital approaches to cartographic heritage, ed. E. Livieratos, Saloniki 2016.

Editionswissenschaftliches Kolloquium 2015. Die Geschichte im Bild, Hrsg. H. Flachenecker, K. Kopiński, J. Tandecki, Torun 2016.

Galicja na józefinskiej mapie topograficznej 1779-1783, t. 1, cz. A, sekcje 1-30: Die Josephinische Landesaufnahme von Galizien 1779-1783, wyd. W. Bukowski, B. Dybaś, Z. Noga, Kraków 2012.

Galicja na józefinskiej mapie topograficznej 1779-1783, t. 1, cz. B: Faksymilia map 1-30, wyd. W. Bukowski, B. Dybaś, Z. Noga, Kraków 2012.

Gochna M., Polish nobility seals in the "recognitiones" of the Kalisz district in 1591. The perspective of an Edition, w: Editionswissenschaftliches Kolloquium 2015. Die Geschichte im Bild, Hrsg. H. Flachenecker, K. Kopiński, J. Tandecki, Toruń 2016.

Górska-Gołaska K., Stownik historyczno-geograficzny ziem polskich w średniowieczu, w: Instytut Historii Polskiej Akademii Nauk 1953-2003, red. S.K. Kuczyński, Warszawa 2003.

Historical Atlas of Poland in the $2^{\text {nd }}$ half of the $16^{\text {th }}$ century: voivodeships of Cracow, Sandomierz, Lublin, Sieradz, Eęczyca, Rawa, Ptock and Mazovia, ed. M. Słoń, Frankfurt am Main 2014.
Instytut Historii Polskiej Akademii Nauk 1953-2003, red. S.K. Kuczyński, Warszawa 2003.

Jurek T., Średniowieczny katalog biskupów poznañskich w Roczniku lubińskim ukryty, „Studia Zródłoznawcze", 54, 2016.

Laberschek J., Sieć wodna średniowiecznego Krakowa i jej gospodarcze wykorzystanie, Warszawa 2016.

Mapy tematyczne, „Geoportal Infrastruktury Informacji Przestrzennej” (https://www.geoportal.gov.pl/dane/ mapy-tematyczne\#, dostęp: 9 lipca 2019).

Mazowsze $w$ drugiej potowie XVI w., red. W. Pałucki, Warszawa 1973 (Atlas historyczny Polski. Mapy szczegółowe XVI wieku, 7).

Najstarsza pleszewska ksiega radziecka. Zapiski z lat 1485-1519, wyd., przet. i oprac. A. Kozak, Poznań 2014.

Pałucki W., Przedmowa, w: S. Wojciechowski, Województwo lubelskie $w$ drugiej potowie XVI w., Warszawa 1966 (Atlas historyczny Polski, Mapy szczegółowe XVI wieku, 3).

Panecki T., Związek T., The so-called Dutch colonization in $18^{\text {th }} c$. Greater Poland: research project on AtlasFontium.pl WebGIS platform, w: Digital approaches to cartographic heritage, ed. E. Livieratos, Saloniki 2016.

Progress in cartography, ed. G. Gartner, M. Jobst, H. Huang, Cham 2016.

Rutkowski H., Atlas historyczny Polski, w: Towarzystwo Nankowe Warszawskie. Sto lat dziatalności, red. E. Wolnicz-Pawłowska, W. Zych, Warszawa 2009.

Rutkowski H., Work on the historical atlas of the sixteenth-century Poland, „Polish Carthographical Review", 50 (4), 2018.

Słon M., Foreword to the British edition, w: Historical Atlas of Poland in the $2^{\text {nd }}$ half of the $16^{\text {th }}$ century: voivodeships of Cracow, Sandomierz, Lublin, Sieradz, Eęczyca, Rawa, Ptock and Mazovia, ed. M. Słoń, Frankfurt am Main 2014.

Stownik historyczno-geograficzny ziem polskich w średniowieczu. Edycja elektroniczna, red. T. Jurek, 20102016 (http://www.slownik.hppan.edu.pl/index.php, dostęp: 26 czerwca 2019).

Szady B., Geografia historyczna w Polsce - rozwój i perspektywy, „Studia Geohistorica”, 1, 2013.

Szady B., Spatio-temporal databases as research tool in historical geography, „Geographia Polonica”, 89 (3), 2016.

Szyszka J., Formowanie i organizacja dóbr monarszych $w$ ziemi lwowskiej od potowy XIV do poczatku XVI wieku, Kraków 2016.

Wielkopolska w drugiej potowie XVI wieku, red. K. Chłapowski, M. Słoń, Warszawa 2017 (Atlas historyczny Polski. Mapy szczegółowe XVI wieku, 4).

Wilska M., Atlas Historyczny Polski, w: Instytut Historii Polskiej Akademii Nauk 1953-2003, red. S.K. Kuczyński, Warszawa 2003.

\section{Studia Geohistorica • Nr 07.2019}


Wojciechowski S., Województwo lubelskie w drugiej potowie XVI w., Warszawa 1966 (Atlas historyczny Polski, Mapy szczegółowe XVI wieku, 3).

Województwo krakowskie w drugiej potowie XVI w., red. H. Rutkowski, Warszawa 2008 (Atlas historyczny Polski. Mapy szczegółowe XVI wieku, 1).

Województwo lubelskie $w$ drugiej potowie XVI wieku, red. W. Pałucki, oprac. S. Wojciechowski, Warszawa 1966 (Atlas historyczny Polski. Mapy szczegółowe XVI wieku, 3).
Województwo sandomierskie w drugiej potowie XVI w., red. W. Pałucki, Warszawa 1993 (Atlas historyczny Polski. Mapy szczegółowe XVI wieku, 2).

Województwo sieradzkie i województwo tęczyckie w drugiej potowie XVI w., red. H. Rutkowski, Warszawa 1998 (Atlas historyczny Polski. Mapy szczegółowe XVI wieku, 5).

Ziemie polskie Korony w XVI w. Przestrzenna baza danych (http://www.atlasfontium.pl/index.php?article=korona, dostęp: 26 czerwca 2019).

\section{Place of the Institute of History of the Polish Academy of Sciences in Future Geographical and Historical Research in Poland}

\section{Summary}

The Department of Historical Atlas at the Institute of History of the Polish Academy of Sciences has been preparing the series "Historical Atlas of Poland. Detailed Maps of the $16^{\text {th }}$ Century" since 1953. The work will be finished in 2020 . Traditionally, the publication of the last volumes is accompanied by the access to a database covering the entire lands of the Polish Crown and the editions of the most important sources used in the course of the work. The scientific activity of team members also covered other topics. Together with the Historical-Geographical Dictionary of the Polish Lands in the Middle Ages, the Department of Historical Atlas makes a strong centre of geographical and historical research of international renown. Despite this, the financial situation of the Institute and the gradual change of its profile calls into question its continued existence. It would be advisable to reverse this trend and give priority to multiyear team projects combining documentary and purely research tasks. This would make it possible to expand the field of geographical and historical research to include new areas (Ruthenian Lands), new periods (the $18^{\text {th }}$ century) and research problems ("Historical Atlas of Polish Towns and Cities"). It would also facilitate the undertaking of new ventures in the field of source editing and methodological reflection and would be associated with the creation of new IT tools.

dr hab. Marek Słoń - profesor Instytutu Historii im. Tadeusza Manteuffla PAN, kierownik Zakładu Atlasu Historycznego. Jego zainteresowania badawcze obejmują dzieje religijności i miast w średniowieczu, geografię historyczną i edytorstwo źródeł

(marek.slon@ihpan.edu.pl)

Marek Stoń, Dr. hab. - professor at the Institute of History, Polish Academy of Sciences, head of the Department of Historical Atlas; his scholarly interests include the medieval history of religions and cities, historical geography and source editing (marek.slon@ihpan.edu.pl) 